\title{
MANAJEMEN PELAYANAN PRIMA DALAM MENGUATKAN JAMAAH HAJI DAN UMRAH BIRO KHUSUS QOSHWA TOURS AND TRAVEL CIREBON
}

Firman Agung Amami, Daimah

IAI Bunga Bangsa Cirebon, Indonesia

Email: firmanagung@gmail.com, marwadaimah@gmail.com

\section{Abstrak}

Latar belakang: Manajemen pelayanan prima dapat menguatkan jamaah haji dan umrah biro khusus qoshwa tours and travel cirebon. Kajian ini dilatar belakangi penyelenggaraan ibadah haji dan umrah yang dinilai kurang efektif dan efisien, yang mana hal ini turut mempengaruhi pemberian pelayanan jamaah haji dan umrah secara maksimal.

Tujuan penelitian: Penelitian ini bertujuan untuk mengetahui bagaimana manajemen pelayanan prima dapat menguatkan jamaah haji dan umrah biro khusus qoshwa tours and travel cirebon.

Metode penelitian: Penelitian ini merupakan penelitian kualitatif yang berupa data primer dan sekunder. Data-data diperoleh melalui observasi, wawancara, dan studi dokumen. Datadata yang terkumpul kemudian dianalisis dengan analisis deskriptif kualitatif untuk mengetahui jawaban atas pokok permasalahan yang telah dirumuskan.

Hasil penelitian: Manajemen pelayanan prima Qoshwa Tours and Travel dengan memperlihatkan penguatan jamaah, dengan demikian mempermudah jamaah terhadap manajemen pelayanan Qoshwa Tours and Travel. Manajemen pelayanan yang digunakan Qoshwa Tours and Travel adalah pelayanan maksimal kepada jamaah haji dan umrah baik dari administrasi, akomodasi, transportasi, kesehatan dan konsumsi.

Kesimpulan: Qoshwa Tours and Travel sudah mengimplementasikan manajemen pelayanan prima dengan cukup baik, karena di dalamnya memberikan pelayanan yang baik dari mulai administrasi, akomodasi, transportasi, kesehatan dan konsumsi. Karyawan Qoshwa Tours and Travel memberikan pelayanan yang cukup maksimal kepada calon jamaah haji dan umrah.

Kata kunci: Manajemen Pelayanan prima, Jamaah Haji, Umrah, Qoshwa Tours and Travel Cirebon

\section{Abstract}

Background: Excellent service management can strengthen hajj and umrah pilgrims, a special bureau of qoshwa tours and travel cirebon. This study is motivated by the implementation of the Hajj and Umrah pilgrimages which are considered to be less effective and efficient, which also affects the provision of services for Hajj and Umrah pilgrims to the maximum.

Research objectives: This study aims to determine how excellent service management can strengthen pilgrims for Hajj and Umrah, the special bureau of Qoshwa tours and travel Cirebon.

Research method: This research is a qualitative research in the form of primary and secondary data. The data were obtained through observation, interviews, and document studies. The data collected was then analyzed by qualitative descriptive analysis to find out the answers to the main problems that have been formulated.

The results of the study: Excellent service management of Qoshwa Tours and Travel by showing the strengthening of the congregation, thereby making it easier for the congregation to manage the service of Qoshwa Tours and Travel. The service management used by Qoshwa Tours and Travel is the maximum service for Hajj and Umrah pilgrims from administration, accommodation, transportation, health and consumption.

Conclusion: Qoshwa Tours and Travel has implemented excellent service management quite well, because it provides good services from administration, accommodation, transportation, health and consumption. Qoshwa Tours and Travel employees provide maximum service to prospective Hajj and Umrah pilgrims.

\begin{tabular}{ll}
\hline & Firman Agung Amami, Daimah. (2021). Manajemen Pelayanan Prima dalam Menguatkan \\
& Jamaah Haji dan Umrah Biro Khusus Qoshwa Tours and Travel Cirebon. Co-Value: Jurnal \\
How to cite: & Ekonomi, Koperasi Kewirausahaan Vol 12(3): 122-129 \\
\hline E-ISSN: & https://greenpublisher.id/
\end{tabular}




Manajemen Pelayanan Prima dalam Menguatkan
Jamaah Haji dan Umrah Biro Khusus Qoshwa Tours and
Travel Cirebon

Keywords: Excellent Service Management, Pilgrims Hajj, Umrah, Qoshwa Tours and Travel Cirebon

Diterima: 26-11-2021; Direvisi: 6-12-2021; Disetujui: 6-12-2021

\section{PENDAHULUAN}

Ibadah haji dan umrah merupakan salah satu bentuk ibadah murni yang diwajibkan atas setiap muslim yang mampu.(Lestari, 2019) Kewajiban ini merupakan rukun Islam yang kelima, karena haji merupakan kewajiban, maka setiap orang yang mampu, apabila tidak melaksanakannya, ia berdosa, dan apabila dilakukan ia mendapatkan pahala.(MINDASARI, 2019)

Dalam pelaksanaan ibadah haji dan umrah terdapat dua sisi yang harus diperhatikan dalam pelaksanaannya yaitu, dalam hal pelaksanaannya di dalam negeri (Indonesia) dan di tanah suci (Makkah).(Kifli, 2010) Pada standar pelayanan di tanah air banyak yang harus diperhatikan dalam hal pembinaannya seperti dalam pelayanan jasa (pembayaran setoran ONH ke bank, pengurusan dokumen haji dan umrah, pemeriksaan kesehatan calon jamaah), bimbingan manasik, (materi bimbingan, metode dan waktu bimbingan), penyediaan perlengkapan, dan konsultasi keagamaan.(Pebrianti, n.d.) Sedangkan standar pelayanan ibadah haji dan umrah di tanah suci adalah pelayanan akomodasi, transportasi, konsumsi, serta kesehatan para jamaah haji.

Akan tetapi, penyelenggaraan ibadah haji dan umrah dewasa ini dinilai kurang efektif dan efisien, yang mana hal ini turut mempengaruhi kualitas pemberian pelayanan dan perlindungan pada jamaah haji dan umrah.(RENHAT, 2021) Agar tujuan pelaksanaan ibadah haji dan umrah selalu sukses dan mencapai target yang ingin dicapai, maka perlu adanya manajemen, baik manajemen dibidang pelayanan, penyuluhan dan bimbingan, manasik dan sebagainya.(RENHAT, 2021) Sehingga apa yang menjadi citacita jamaah dalam menunaikan ibadah haji dan umrah ini bisa di peroleh secara sempurna dan memuaskan.

Dalam masalah ketidak efektif dan efesienan penyelenggaraan haji dan umrah ini, hal itu menjadi lirikan tersendiri bagi biro-biro perjalanan haji dan umrah yang mana mereka berlomba-lomba menawarkan produk-produk mereka kepada calon jamaah. seperti pembinaan, pelayanan dan perlindungan dengan kelebihan fasilitas yang berbeda.

Salah satu dari layanan biro jasa perjalanan haji dan umrah adalah biro perjalanan ibadah umrah dan haji khusus Qoshwa Tours and Travel Kabupaten Cirebon, yang tepatnya itu berlokasi di Jl. Dewi Sartika No. 08 Kelurahan Kenanga Kecamatan Sumber, Cirebon. Merupakan suatu lembaga usaha swasta yang bergerak pada bidang pariwisata khususnya haji \& umrah yang mana lembaga ini mencoba membantu melancarkan pelaksanaan ibadah haji dan umrah di Indonesia yang selama ini masih kurang dalam segi pelayanan.(Muhammad \& Hamzah, 2020) Dimana pelayanan tersebut juga harus sesuai standar pelayanan haji yang telah diatur oleh undang-undang tentang ibadah haji dan umrah.(Yusni, 2015)

Mengapa pelayanan, karena biro perjalanan ibadah umrah dan haji khusus Qoshwa Tours and Travel Cirebon menyesuaikan dengan standar peraturan yang diatur oleh pemerintah dengan berdasarkan Undang-Undang Nomor 13 Tahun 2008 Tentang Penyelenggaraan Ibadah Haji, lebih tepatnya BAB XII Pasal 33 mengenai Penyelenggaraan Ibadah Haji Khusus yang berbunyi "penyelenggaraan ibadah haji khusus dilaksanakan untuk jamaah haji yang memerlukan pelayanan khusus dibidang bimbingan ibadah, transportasi, akomodasi, konsumsi, dan pelayanan kesehatan"

Maraknya haji non reguler atau sering disebut haji furroda yang berbasis abalabal, sehingga mengakibatkan kurangnya kepercayaan dari para calon jamaah untuk 
menggunakan biro-biro yang ada.(Zazilah, n.d.) Untuk menghindari itu semua diperlukannya manajemen pelayanan yang baik dan benar pada biro-biro traveling yang menangani haji dan umrah. Agar para calon jamaah dapat merasakan kenyamanan untuk menggunakan jasa dari biro-biro tersebut.(Zazilah, n.d.)

Tidak hanya haji yang berbasis abal-abal, banyak kita jumpai lembaga-lembaga penyedia jasa haji dan umroh yang membawa kabur dana nasabahnya dan banyak calon jemaah haji yang gagal menunaikan ibadah haji kerena tertipu oleh lembaga-lembaga penyedia jasa haji dan umroh, seperti yang terjadi pada akhir tahun 2017 penipuan yang dilakukan oleh First Travel, direktur tindak pidana umum Bareskrim Polri Brigjen Pol Herry Udolf Nahak mengatakan, jumlah korban yang belum di berangkatkan agen perjalanan First Travel sebanyak 58.682 orang kalau di total ada Rp 848.700.100.000 dan jumlah tersebut belum termaksud utang-utang yang belum di bayar ke sejumlah pihak. Tidak hanya itu, baru-baru ini terkungkap pula pada awal tahun 2018 penipuan dan penggelapan yang di lakukan agen perjalan haji PT Usmaniyah Hannien Tour yang melakukan penggelapan sebesar 41 miliar dari 10 kantor anak cabang dan tercatat sebanyak 4.126 jamaah seluruh Indonesia.(Alpiansyah, 2018) Banyaknya masyarakat yang tertipu oleh biro perjalanan haji dan umroh memiliki dampak kekawatiran masyrakat untuk menggunakan biro perjalan haji dan umroh.(Alpiansyah, 2018)

Adanya hal seperti itu, biro perjalanan ibadah umrah dan haji khusus Qoshwa Tours and Travel perlu memperbaiki kegiatan pelayanannya secara terpadu agar para calon jamaah dapat menggunakan biro traveling yang ditawarkan. Mengingat semakin banyak pesaing dalam hal biro perjalanan dan semakin banyak pula biro-biro yang menawarkan berbagai fasilitas pelayanan yang disediakan.(Syahputra, 2017) Sehingga para calon jamaah haji dan umrah bisa memilah-milah biro mana yang terbaik dalam pelayanannya.(Zazilah, n.d.)

Penulis menjadikan biro perjalanan ibadah umrah dan haji khusus Qoshwa Tours and Travel Cirebon sebagai obyek penelitian karena biro pelayanan tersebut menerapkan manajemen yang berorientasi pada peningkatan mutu pelayanan. Dikarenakan dengan maraknya biro haji yang belum resmi terdaftar di Kementerian Agama membuat pelayanan haji dan umrah di Indonesia kurang maksimal hanya karena adanya biro-biro yang tidak bertanggung jawab (RENHAT, 2021). Maka dari itu penulis ingin meneliti biro perjalanan ibadah umrah dan haji khusus Qoshwa Tours and Travel Cirebon apakah sudah sesuai cara pelayanannya dengan pihak biro yang terkait yang mana akan meningkatkan minat para jamaah haji dan umrah.

Berdasarkan masalah diatas maka tujuan dari penelitian ini adalah untuk mengetahui bagaimana manajemen pelayanan prima jamaah haji dan umrah biro khusus Qoshwa Tours and Travel Cirebon, bagaimana pelayan prima dapat menguatkan jamaah haji dan umrah biro khusus Qoshwa Tours and Travel Cirebon serta hal-hal apa saja yang menjadi pendukung dan penghambat biro khusus Qoshwa Tours and Travel Cirebon.

\section{METODE PENELITIAN}

Agar penelitian berjalan sesuai dengan yang diharapkan, maka perlu direncanakan secara cermat dengan cara membuat desain penelitian terlebih dahulu. Penelitian kualitatif dapat dipandang sebagai penelitian yang partisipatif, dimana desain penelitiannya fleksibel atau bisa dimungkinkan untuk diubah guna menyesuaikan dari rencana yang telah dibuat, dengan gejala yang ada pada tempat penelitian yang sebenarnya (SARI, 2020). 
Penelitian ini dilakukan di Pada Biro Perjalanan Ibadah Haj dan Umrah Qoshwa Tours and Travel Cirebon. Waktu penelitian dilakukan pada tanggal 1 April 2019 s.d. 30 Mei 2019

Penelitian ini mengambil data dari berbagai sumber, seperti sumber secara langsung, dokumen-dokumen maupun karya tulis yang relevan dengan penelitian yaitu berkaitan dengan manajemen pelayanan prima dapat menguatkan jamaah haji dan umrah biro khusus Qoshwa tours and travel Cirebon.(Mustakim, n.d.) Adapun penelitian ini, teknik pengumpulan data yang digunakan adalah wawancara, observasi, angket, sumber data Qoshwa Tours and Travel, serta studi dokumen.

\section{HASIL DAN PEMBAHASAN}

\section{A. Hasil Penelitian Qoshwa Tours and Travel Cirebon}

1. Apakah manajemen pelayanan prima dapat menguatkan jamaah haji dan umrah di biro Qoshwa Tours and Travel Cirebon?

Dari beberapa jawaban wawancara yang dilakukan penulit dengan beberapa Error! Hyperlink reference not valid.koresponden dapat disimpulkan bahwa manajemen pelayanan yang prima yang dilakukan oleh biro haji dan umrah Qoshwa Tours and Travel Cirebon banyak mempengaruhi penguatan jamaah haji dan umrah, karena manajemen pelayanan yang baik akan berdapak pada jamaah yang merasa puas, begitupun sebaliknya.

2. Bagaimana manajemen pelayanan prima jamaah haji dan umrah biro Qoshwa Tours and Travel Cirebon?

Manajemen pelayanan yang dilakukan dalam meningkatkan pelayanan prima adalah melakukan kunjungan (silaturrokhim) kerumah para calon jamaah untuk menjalin hubungan kekeluargaan dengan maksud untuk melakukan transaksi pendaftaran yang dilakukan jamaah yang kurang yakin, dan memberikan pelayanan kepada jamaah dengan pelayanan maksimal, menjaga amanah dan bimbingan yang persuasif.(Arumsari, 2019) Manajemen pelayanan yang dilakukan dalam meningkatkan pelayanan prima adalah dengan memberikan informasi atau komunikasi aktual kepada jamaah haji maupun umrah, melalui media WhatsApp (WA) atau melalui E-maill.

Dari beberapa jawaban wawancara yang dilakukan penulit dengan beberapa koresponden, biro khusus Qoshwa Tours and Travel Cirebon menggunakan beberapa pelayanan yang bertujuan untuk menguatkan jamaah haji dan umrah agar para jamaah merasa puas, diantaranya yaitu, melakukan kunjungan (silaturrokhim) kerumah para calon jamaah untuk menjalin hubungan kekeluargaan dengan maksud untuk melakukan transaksi pendaftaran yang dilakukan jamaah yang kurang yakin, dan memberikan pelayanan kepada jamaah dengan pelayanan maksimal, menjaga amanah, bimbingan yang persuasif, menerima pendaftaran melauli WhatsApp (WA) atau yang sejenisnya, dan sedikit banyaknya jamaah mengetahui program itu.

3. Bagaimana penerapan pelayanan administrasi yang dilakukan biro haji dan umrah Qoshwa Tours and Travel Cirebon?

Biro Qoshwa Tours and Travel melakukan penerapan administrasi pendaftaran dengan cara mengisi form-form yang telah disediakan petugas administrasi dengan menyiapkan: 1). formulir, 2). Fotocopy KTP, 3). Fotocopy KK, 4). Fotocopy Akta kelahiran dan paspor bagi yang sudah memilikinya, bagi yang belum memilikinya akan dibantu membuat paspor ke Dinas Imigrasi.

Dari beberapa jawaban wawancara yang dilakukan penulit dengan beberapa koresponden dapat disimpulkan bahwa, biro Qoshwa Tours and Travel melakukan penerapan administrasi pendaftaran cukup baik, dengan cara mengisi form-form yang 
telah disediakan petugas administrasi dengan menyiapkan: 1). formulir, 2). Fotocopy KTP, 3). Fotocopy KK, 4). Fotocopy Akta kelahiran dan paspor bagi yang sudah memilikinya, bagi yang belum memilikinya akan dibantu membuat paspor ke Dinas Imigrasi dan pihak biro haji dan umrah juga menerima pendaftaran administrasi melalui media online.(Sulaiman, n.d.)

4. Bagaimana penerapan pelayanan akomodasi yang dilakukan biro haji dan umrah Qoshwa Tours and Travel Cirebon?

Dari beberapa jawaban wawancara yang dilakukan penulit dengan beberapa koresponden dapat disimpulkan bahwa penerapan pelayanan akomodasi yang dilakukan Qoshwa Tours and Travel Cirebon dikatakan baik, karena dari jamaah yang di wawancarai mayoritas merasa puas dari pelayanan akomodasi Qoshwa Tours and Travel Cirebon, yaitu Akomodasi yang dilakukan setelah melakukan administrasi jamaah akan mendapatkan akomodasi berupa (tas koper, tas selempang, seragam batik, mukenah, baju ihram, dan buku pedoman). Kemudian ketika berada di Arab Saudi, jamaah akan di fasilitasi Hotel bintang 4 atau 5, Tour Guid, transportasi bis AC, transportasi pesawat yang baik dengan pengamanan kesehatan jamaah yang mana disertai dokter.(Fithri, n.d.)

5. Bagaimana penerapan pelayanan konsumsi yang dilakukan biro haji dan umrah Qoshwa Tours and Travel Cirebon?

Dari beberapa jawaban wawancara yang dilakukan penulit dengan beberapa koresponden dapat disimpulkan bahwa penerapan pelayanan konsumsi yang dilakukan Qoshwa Tours and Travel Cirebon di katakan sudah baik dan cukup memuaskan para jamaah haji maupun umrah, karena Qoshwa Tours and Travel Cirebon mempersiapkan konsumsi dengan menu makanan Internasional, menu makanan Arab Saudi dan menu makanan Indonsesia dengan konteks tradisional yang halal.

6. Bagaimana penerapan pelayanan transportasi yang dilakukan biro haji dan umrah Qoshwa Tours and Travel Cirebon?

Dari beberapa jawaban wawancara yang dilakukan penulit dengan beberapa koresponden dapat di simpulkan bahwa Qoshwa Tours and Travel Cirebon melayani jamaah haji dan umrah dalam penerapan transportasi adalah yang paling unggul yaitu sangat baik. Karena transportasi yang diberikan secara maksimal (full AC), yaitu menggunakan jasa pesawat Suadi Arabian dengan penerbangan dari Bandara Soekarno Hatta menuju Bandara Jeddah King Abdul Aziz yang tidak melakukan transit, lalu bis yang sudah disiapkan khusu oleh provider yang di Arab Saudi.

7. Bagaimana penerapan pelayanan kesehatan yang dilakukan biro haji dan umrah Qoshwa Tours and Travel Cirebon?

Dari beberapa jawaban wawancara yang dilakukan penulit dengan beberapa koresponden dapat di simpulkan bahwa Qoshwa Tours and Travel Cirebon melayani jamaah haji dan umrah dalam penerapan kesehatan dikatakan baik, karena jamaah meras puas untuk pelayanan kesehatan tersebut khusunya jamaah yang sudah berumur panjang. Qoshwa Tours and Travel Cirebon dalam melayani kesehatan yang diberikan untuk jamaah yaitu melakukan tes kesehatan sebelum pemberangkatan, memberikan faksin biometrik dan miningitis, menyiapkan doktor spesialis di dalam pesawat (pemberangkatan dan pemulangan) dan doket untuk di Arab Saudi.

8. Program apa saja yang ada dalam biro haji dan umrah Qoshwa Tours and Travel Cirebon?

Dari beberapa jawaban wawancara yang dilakukan penulit dengan beberapa koresponden dapat di simpulkan bahwa Qoshwa Tours and Travel Cirebon memiliki program yang di pasarkan dengan tujuan untuk kepentingan jamaah haji dan umrah agar merasa puas, diantaranya, Program paket haji dan umrah reguler, paket haji dan umrah tabungan, paket haji dan umrah plus (+) dan paket Ramadhan. 
Berdasarkan data dari Qoshwa Tours and Travel Cirebon, biro ini memiliki faktor pendukung dan penghambat.

Faktor pendukung Qoshwa Tours and Travel Cirebon adalah:

a. Letak geografis yang strategis.

b. Publikasi dari pihak Qoshwa Tours and Travel yang terus menerus melalui beberapa media yang cukup membantu pemasaran dari lembaga tersebut.

c. Qoshwa Tours and Travel memiliki naungan dari PT. Masruchin Centre Cerbon yang di daerah Cirebon yang cukup di kenal terutama di Kota Cirebon.

d. Mempunyai banyak link atau pihak kerja sama yang cukup sehingga membuat Qoshwa Tours and Travel Cirebon tetap bertahan.

e. Tidak pernah terjadi wanprestasi dalam pelaksanaan pelayanan di biro haji dan umrah Qoshwa Tours and Travel.

Sedangkan faktor penghambat dari Qoshwa Tours and Travel Cirebon adalah:

a. Timbulnya persaingan yang ketat dikarenakan banyaknya biro-biro penyelenggaraan ibadah haji dan umrah, sehingga akan mengurangi kuota yang diberikan kepada setiap biro-biro penyelenggaraan ibadah haji dan umrah.

b. Harga dolar semakin meningkat akan berdampak pada biaya perjalanan ibadah haji maupun ibadah umrah.

c. Karyawan yang menghendel menejemen dalam Qoshwa Tours and Travel itu sendiri, namun tidak menjadikan masalah yang besar untuk menjalankan tugasnya masing-masing dalam pekerjaannya tersebut.

d. Kurangnya pengetahuan dari jamaah dalam melaksanakan ibadah haji maupun umrah. Namun, Qoshwa Tours and Travel Cirebon terus membimbingnya agar dalam melaksanakan ibadahnya sesuai syariat.

\section{KESIMPULAN}

Berdasarkan penelitian skripsi yang telah dilakukan, maka dapat disimpulkan bahwa manajemen pelayanan prima haji dan umrah di biro khusus Qoshwa Tours and Travel Cirebon sudah baik karena manajemen pelayanan yang dilakukan dalam meningkatkan pelayanan prima. Pelayanan prima yang dilakukan Qoshwa Tours and Travel Cirebon adalah dapat melakukan transaksi yang dilakukan di rumah jamaah dengan maksud untuk mempererat hubungan kekeluargaan, dapat melakukan pendaftaran melalui media WhatsApp (WA), memberikan pelayanan kepada jamaah dengan pelayanan maksimal, menjaga amanah, bimbingan yang persuasif dan meliliki program paket haji dan umrah reguler, paket haji dan umrah tabungan, paket haji dan umrah plus (+) serta paket Ramadhan untuk menguatkan jamaah.

Pelayanan prima yang dilakukan biro khusus Qoshwa Tours and Travel Cirebon tidak terlepas dari kegiatan pelayanan haji dan umrah, yaitu administrasi yang baik dengan tenaga kerja yang baik dan ramah, akomodasi yang memadai untuk jamaah haji dan umrah, konsumsi yang baik sehat dan halal yang disediakan, transportasi yang nyaman, dan pelayanan kesehatan yang maksimal.

Faktor pendukung Qoshwa Tours and Travel Cirebon adalah Letak geografis yang strategis, Publikasi dari pihak Qoshwa Tours and Travel yang terus menerus melalui beberapa media yang cukup membantu pemasaran dari lembaga tersebut, Qoshwa Tours and Travel memiliki naungan dari PT. Masruchin Centre Cerbon yang di daerah Cirebon yang cukup di kenal terutama di Kota Cirebon, Mempunyai banyak link atau pihak kerja sama yang cukup sehingga membuat Qoshwa Tours and Travel Cirebon tetap bertahan, Tidak pernah terjadi wanprestasi dalam pelaksanaan pelayanan di biro haji dan umrah 
Qoshwa Tours and Travel. Sedangkan faktor penghambat dari Qoshwa Tours and Travel Cirebon adalah Timbulnya persaingan yang ketat dikarenakan banyaknya biro-biro penyelenggaraan ibadah haji dan umrah, sehingga akan mengurangi kuota yang diberikan kepada setiap biro-biro penyelenggaraan ibadah haji dan umrah, harga dolar semakin meningkat akan berdampak pada biaya perjalanan ibadah haji maupun ibadah umrah, Karyawan yang menghendel menejemen dalam Qoshwa Tours and Travel itu sendiri, namun tidak menjadikan masalah yang besar untuk menjalankan tugasnya masing-masing dalam pekerjaannya tersebut, kurangnya pengetahuan dari jamaah dalam melaksanakan ibadah haji maupun umrah. Namun, Qoshwa Tours and Travel Cirebon terus membimbingnya agar dalam melaksanakan ibadahnya sesuai syariat.

\section{BIBLIOGRAFI}

Alpiansyah, A. (2018). ANALISIS STRATEGI PEMASARAN PRODUK SIMPANAN HAJI DAN UMROH PADA KOPERASI SIMPAN PINJAM PEMBIAYAN SYARIAH (Studi Pada BMT Al Ihsan Binaul Ummah Metro Lampung). UIN Raden Intan Lampung.

Arumsari, O. P. D. (2019). Implementasi customer relations management di perusahaan travel umrah dan haji plus Mina Wisata Islami Surabaya. UIN Sunan Ampel Surabaya.

Fithri, A. A. (n.d.). Manajemen Pelayanan Jamaah Haji Pada PT. Madani Bina Bersama, Kecamatan Tebet, Kota Jakarta Selatan. Fakultas Ilmu Dakwah dan Ilmu Komunikasi Universitas Islam Negeri Syarif ....

Kifli, D. (2010). Manajemen pelayanan jamaah haji dan umrah PT Patuna Tour dan Travel.

Lestari, W. (2019). Nilai-nilai pendidikan yang terkandung dalam ibadah haji. IAIN Padangsidimpuan.

MINDASARI, H. (2019). PELAKSANAAN KEMENTERIAN AGAMA DALAM MEMBERIKAN PELAYANAN PENYELENGGARAAN IBADAH HAJI REGULER DI KABUPATEN KAMPAR. UNIVERSITAS ISLAM NEGERI SULTAN SYARIF KASIM RIAU.

Muhammad, M., \& Hamzah, A. A. (2020). Peran Manajemen dalam Mengelola Wisata Religi untuk Meningkatkan Kualitas Pelayanan Ziarah Pada Jamaah Umroh PT.

Meida Wisata. Jurnal AL-MIZAB Jurnal Kajian Haji, Umrah Dan Keislaman, 1(1).

Mustakim, Y. (n.d.). Evaluasi Pelayanan Prima Jama'ah Haji Khusus Pada PT. Proconfo Indah Di Jakarta Selatan Tahun 2016. Fakultas Ilmu Dakwah dan Ilmu Komunikasi Universitas Islam Negeri Syarif ....

Pebrianti, K. A. B. W. (n.d.). ANALISIS FAKTOR YANG MEMPENGARUHI KEPUTUSAN PEMILIHAN TRAVEL UMROH. Equator Journal of Management and Entrepreneurship (EJME), 9(3).

RENHAT, R. P. (2021). IMPLEMENTASI PELAYANAN BIRO PERJALANAN HAJI DAN UMROH PADA KHALIFA TRAVEL DALAM PEMBINAAN JAMAAH BANDAR LAMPUNG. UIN Raden Intan Lampung.

SARI, N. (2020). STRATEGI PEMASARAN JASA PENDIDIKAN DI SEKOLAH MENENGAH PERTAMA (SMP) MUHAMMADIYAH 4 PALEMBANG. UIN RADEN FATAH PALEMBANG.

Sulaiman, J. (n.d.). Strategi pelayanan haji kantor kementerian Agama Kota Jakarta Barat Terhadap Jamaah Haji Tahun 2009.

Syahputra, N. (2017). Analisis Sistem Pelayanan Haji dan Umrah Pada PT Malindo Makkah Madinah di Medan. Jurnal Bisnis Corporate, 3(2). 
Manajemen Pelayanan Prima dalam Menguatkan e-ISSN: 2809-8862

Jamaah Haji dan Umrah Biro Khusus Qoshwa Tours and p-ISSN: 2086-3306 Travel Cirebon

Yusni, M. A. (2015). Studi Tentang Pelayanan Haji Di Kementerian Agama Kota Samarinda. EJoournal Ilmu Pemerintahan, 3.

Zazilah, R. S. (n.d.). Manajemen Pelayanan Biro Perjalanan Haji Dan Umrah PT. Chairul Umam Addauli Jambi.

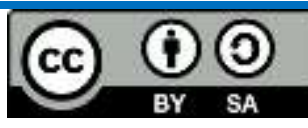

This work is licensed under a Creative Commons Attribution-ShareAlike 4.0 International License 